Article

\title{
Variability and Site Dependence of Grain Mineral Contents in Tetraploid Wheats
}

\author{
Laura Del Coco ${ }^{1}$ (D), Barbara Laddomada ${ }^{2}$, Danilo Migoni ${ }^{1,3}$, Giovanni Mita ${ }^{2}$, \\ Rosanna Simeone ${ }^{4}$ and Francesco Paolo Fanizzi 1,3,*D \\ 1 Department of Biological and Environmental Sciences and Technologies (Di.S.Te.B.A.), University of Salento, \\ via Monteroni, 73100 Lecce, Italy; laura.delcoco@unisalento.it (L.D.C.); danilo.migoni@unisalento.it (D.M.) \\ 2 Institute of Sciences of Food Production (ISPA), National Research Council (CNR), via Monteroni, \\ 73100 Lecce, Italy; barbara.laddomada@ispa.cnr.it (B.L.); giovanni.mita@ispa.cnr.it (G.M.) \\ 3 Inter-University Consortium for Research on Chemistry of Metals in Biological Systems (C.I.R.C.M.S.B.), \\ Lecce Research Unit, 73100 Lecce, Italy \\ 4 Department of Soil, Plant \& Food Sciences, Genetics and Plant Breeding Section, University Aldo Moro, \\ via G. Amendola, 165/a 70126 Bari, Italy; rosanna.simeone@uniba.it \\ * Correspondence: fp.fanizzi@unisalento.it; Tel.: +39-0832-299265
}

Received: 10 December 2018; Accepted: 28 January 2019; Published: 31 January 2019

check for updates

\begin{abstract}
Crop production and natural resource use, especially in developing countries, represents one of the most important food sources for humans. In particular, two wheat species (tetraploid, which is mostly used for pasta and hexaploid, which is primarily used for bread) account for about $20 \%$ of the whole calories consumed worldwide. In order to assess the mineral accumulation capability of some popular tetraploid wheat genotypes, a metabolomic (metallomic) approach was used in this study. The metallomic profile related to micro- $(\mathrm{Zn}, \mathrm{Fe}, \mathrm{Cu}, \mathrm{Mn}, \mathrm{Ni}$ and $\mathrm{Cr})$, macro- $(\mathrm{Ca}, \mathrm{Mg}$ and $\mathrm{K})$ and toxic trace elements $(\mathrm{Cd}$ and $\mathrm{Pb}$ ) was obtained by ICP-AES analysis in a large set of tetraploid wheat genotypes (Triticum turgidum L.) that were grown in two different experimental fields. Correlations and multivariate statistical analyses were performed, grouping the samples under two wheat sets, comprising cultivated durum cultivars (T. turgidum subsp. durum) and wild accessions (T. turgidum subsp. dicoccum and subsp. dicoccoides). The site dependence ranking for the selected genotypes with the highest nutrient accumulation was obtained. The significantly higher content of $\mathrm{Mg}$ (among the macronutrients) and the highest levels of Mn, Fe and $\mathrm{Zn}$ (among the micronutrients) were found for wild accessions with respect to durum cultivars. Moreover, the former genotypes were also the ones with the lowest level of accumulation of the trace toxic elements, in particular $\mathrm{Cd}$. According to the performed statistical analyses, the wild accessions appeared also to be less influenced by the different environmental conditions. This is in accord with literature data, indicating the superiority of "old" with respect to modern wheat cultivars for mineral content. Although further studies are required on a wider range of genotypes to confirm these findings, the obtained results could be used to better select the less demanding and better performing cultivars in specific target wheat growing environments.
\end{abstract}

Keywords: tetraploid wheat; metallomics; macronutrients; micronutrients; plants adaptability

\section{Introduction}

Wheat is one of the most important commodities, with a world production of 750 million tons and 220 million ha harvested in 2016, as reported by Faostat [1]. Interestingly, wheat consumption is closely related with the adoption of a "western lifestyle" [2], as well as some countries that are not climatically adapted to wheat cultivation, such as some Sub-Saharan Africa areas [3]. 
Among the wheat species, two types are prevalent: tetraploid wheat $(2 n=28$, genome AABB), which is mostly used for pasta, and hexaploid wheat $(2 n=42$, genome AABBDD), which is primarily used for bread. Together, these wheats account for about $20 \%$ of the whole calories that are consumed worldwide. Considering both types, wheat cultivation occurs in a wide range of environmental and soil conditions, and wheat growers face several challenges to reaching high yield and quality standards that are also sustainable and economically feasible. Among the major challenges, there is the identification of agronomical practices or genotypes that may help in reducing the inputs of fertilizers, herbicides and chemical treatments to counteract biotic or abiotic diseases.

Among tetraploid wheat (Triticum turgidum L.), the subsp. durum is the most cultivated and economically important typically rainfed crop and adapted to the semiarid conditions of the Mediterranean Basin. Indeed, the species T. turgidum also includes other subspecies, displaying a large variability for many traits, such as plant adaptability and defence, or quality traits. This variability is still largely unexplored for genes that could meet the needs for a more sustainable management of wheat cultivation. For instance, the subspecies dicoccoides (Körn. ex Asch. et Graebner) Thell.), the wild progenitor of durum wheat, is well known to accumulate more proteins and minerals in mature grains [4]. Also, the subspecies dicoccum, the direct domesticated progenitor of durum wheat, may carry other interesting traits related to plant adaptability that could be easily transferred into the durum background through breeding programs [5]. The occurrence of such variability could be of particular significance to improve yield, especially in those countries that are undergoing urbanization and industrialization, or to address market expectations with respect to quality, nutrition and health issues.

In general, wheat grains have been considered a primary source of energy (carbohydrates), proteins, vitamins and minerals (especially micronutrients, such as iron and zinc) in human diets [2,3,6-10]. Indeed, the potential benefits of wheat on human health are well known and have been extensively studied [6,11-13]. Besides the major components, several phytochemicals conferring antioxidant properties [14-17] and dietary fibers contribute to reduce the risks for cardiovascular disease and colon cancers [2]. The high variability in those health-promoting components was shown to be influenced by both genetic and environmental factors $[2,13,18,19]$.

To increase the content of minerals in wheat grains, in recent years, several biofortification breeding efforts were undertaken, mainly focused on hexaploid wheat. Those studies led to the release of bred varieties having competitive grain yields and about $30-40 \%$ more $\mathrm{Zn}$ compared with other varieties [20]. Those results were possibly due to the identification of wheat genotypes with elevated Zn contents [21] that were subsequently crossed with modern elite wheat lines that generally do not vary much in terms of mineral contents [22].

Similar studies are mostly missing for tetraploid wheats $[17,23]$. So far, investigations are urgent to assess the current mineral levels in durum cultivars and in other tetraploid wheats subspecies to underpin the extent of genetic variability that is available within the primary gene pool. In fact, the assessment of genetic variation for mineral content is essential for the success of breeding activities that are aimed at developing new micronutrient-rich wheat genotypes that also display high grain yields [24,25]. Some literature data [26-28] indicated the superiority of "old" with respect to modern high-yielding wheat cultivars for mineral contents, however a comprehensive survey in tetraploid wheats is still lacking [28]. Also, more efforts devoted to investigate the influence of different growing sites on mineral accumulation in durum wheat grains would be important to identify precise genotype $x$ environment combinations resulting in higher contents of some micronutrients, such as $\mathrm{Fe}, \mathrm{Zn}, \mathrm{Mn}$ and $\mathrm{Cu}$, which have important physiological functions in humans $[2,3,12,14,15,18,19,24-26,28-30]$.

In order to investigate the genetic variability for mineral content in tetraploid wheats, this study was conducted with the following objectives: (1) to evaluate, by ICP-AES analysis, the metallomic profile related to micro- $(\mathrm{Zn}, \mathrm{Fe}, \mathrm{Cu}, \mathrm{Mn}, \mathrm{Ni}$ and $\mathrm{Cr}$ ), macro- ( $\mathrm{Ca}, \mathrm{Mg}$ and $\mathrm{K})$ and toxic trace elements $(\mathrm{Cd}$ and $\mathrm{Pb})$ in a collection of tetraploid wheats, including durum cultivars and dicoccoides and dicoccum accessions; (2) to investigate the site dependence features exhibited by durum and wild wheat by both 
univariate and multivariate statistical analyses, and (3) to evaluate a possible ranking of exhibited site-dependence among the considered subspecies.

\section{Materials and Methods}

\subsection{Data Collection}

The wheat collection that was analyzed in this study was composed of 25 tetraploid wheat genotypes comprising dicoccum, dicoccoides and durum subspecies of T. turgidum (Table 1). The plant material was grown under conventional farming in the experimental fields of the Department of Soil, Plant and Food Sciences at Valenzano, Italy (site-A) in 2013-2014 [31], and at Policoro, Italy (site B) in 2014-2015 [32]. The plants were grown in a randomized complete block design with three field replicates and plots consisting of $1 \mathrm{~m}$ rows that were $30 \mathrm{~cm}$ apart, with 50 germinating seeds per plot. During the growing season, $120 \mathrm{~kg} / \mathrm{ha} \mathrm{N}$ were applied and standard cultivation practices were adopted. Plots were hand-harvested at maturity.

Table 1. Taxonomic classification of the wheat genotypes considered in the study.

\begin{tabular}{cc}
\hline Genotype & Taxonomic Classification \\
\hline MG5323 & T. turgidum L. subsp. dicoccum \\
MG4343 & T. turgidum L. subsp. dicoccoides \\
MG4330 & T. turgidum L. subsp. dicoccoides \\
MG29896 & T. turgidum L. subsp. dicoccoides \\
Anco Marzio, Aureo, AC Avonlea, Ciccio, Duilio, Fiore, Grecale, Iride, & \\
Isildur, Latino, Latinur, Liberdur, Messapia, Neolatino, Normanno, & T. turgidum L. subsp. durum \\
Preco, Primadur, Saragolla, Svevo, Tiziana, UC1113 & \\
\hline
\end{tabular}

\subsection{Determination of Metal Concentration}

The concentration of macronutrients $(\mathrm{Ca}, \mathrm{Mg}, \mathrm{K})$, micronutrients $(\mathrm{Zn}, \mathrm{Fe}, \mathrm{Cu}, \mathrm{Mn}, \mathrm{Ni}, \mathrm{Cr}$ ) and toxic trace elements $(\mathrm{Cd}, \mathrm{Pb})$ was determined using the Inductively Coupled Plasma Atomic Emission Spectroscopy (ICP-AES) in the whole grains of 25 wheat accessions and cultivars for each site. Wheat samples were mineralized following standard procedures [33]. Briefly, in a Teflon vessel, $0.5 \mathrm{~g}$ of

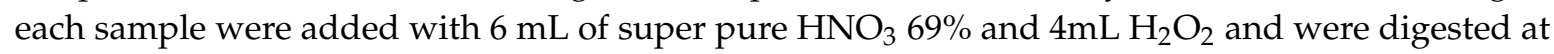
$180^{\circ} \mathrm{C}$ for $10 \mathrm{~min}$ using a Milestone START D microwave digestion system. After mineralization, the samples were cooled at room temperature, diluted to a final volume of $30 \mathrm{~mL}$ with super pure water and filtered. The solutions that were obtained after the mineralization process were subsequently analyzed by a Thermo Scientific iCAP 6000 ICP-AES spectrometer. It should be noted that the obtained metallomic profiles refer to the whole grain wheat mass (upon chemical digestion and ICP analyses). Therefore, no kernel related adjustments were considered since a simple metabolomic approach was used in this study in order to assess the bioaccumulation ability of different wheat species groups.

\subsection{Statistical Analysis}

Standard analysis of variance (One Way-ANOVA) with Tukey's honestly significant difference (HSD) post hoc test was applied to compare the means between the two cultivation sites and for multiple comparisons of groups (wheat type) using the R statistical environment, Version 3.5.1 on a 64 bit Windows machine [34]. The levels of statistical significance were at least at p-values $<0.05$ with a $95 \%$ confidence level. Moreover, the correlation matrix based on Pearson's coefficient was calculated for all the measured elements by using MetaboAnalyst 4.0, which is a web-based tool for the visualization of metabolomics [35,36]. This approach is the most widely used in this type of data $[31,37]$ in order to assess the existence of a possible linear relationship between minerals for both the two cultivation sites [38]. Multivariate statistical analyses and graphics were obtained using SIMCA 14 software, (Sartorius Stedim Biotech, Umeå, Sweden) [39]. Specifically, exploratory data analysis was performed using Principal Component Analysis (PCA), while Projection to Latent Structures 
(PLS)-based methods were used for discriminant analysis and data set comparison. The models were validated using an internal cross-validation default method (7-fold) and were further evaluated with a permutation test (400 permutations) [40,41]. The quality of the models was described by $R^{2}, Q^{2}$ and $p$ values (p[CV-ANOVA], at a 95.0\% confidence level, which were obtained from the analysis of variance testing of cross-validated predictive residuals (CV-ANOVA) [41,42]). To investigate the role of the measured variables in classification, a combination of loadings, variable influence on projection (VIP) parameters and $\mathrm{p}$ (corr) were analyzed. Loadings describe the correlations that the Principal or PLS component has with the original variables. VIP parameters summarize the overall contribution of each variable to the model and $\mathrm{p}$ (corr) represents the loadings scaled as a correlation coefficient (ranging from -1.0 to 1.0) between the model and the original data [43].

\section{Results}

\section{Mineral Composition of Durum and Wild Wheat}

The 25 wheat genotypes were used to assess the potential similarities and/or differences in the mineral content for the considered two harvesting sites (A, Valenzano, Bari, and B, Policoro, Matera) and among the different cultivars. All samples were grown in both the two harvesting sites and three replicates were collected for each sample, reaching a total of 148 (73 and 75 for site A and B, respectively). According to the wheat type, samples were also classified into durum ( 63 for each site, for a total of 126 samples) and wild (10 and 12 for site A and B, for a total of 22 samples).

Average and standard deviation values for concentrations of macro- $(\mathrm{Ca}, \mathrm{K}, \mathrm{Mg})$, micro- $(\mathrm{Cr}$, $\mathrm{Cu}, \mathrm{Fe}, \mathrm{Mn}, \mathrm{Zn})$ and toxic elements $(\mathrm{Cd}, \mathrm{Pb})$, which were expressed in part per million (ppm), were measured for all the studied cultivars and sites and are reported in Supplementary material (Tables S1 and S2). A summary clustering all of the studied cultivars according to the different wheat species (durum and wild) and the two cultivation sites (A and B) is reported in Table 2 and Figure 1. Tukey HSD test was applied for multiple comparisons of groups (wheat type) and One-way ANOVA was applied to compare the means between the two cultivation sites. As expected [44,45], among all the measured elements, the highest concentration was found for $\mathrm{K}$, followed by $\mathrm{Mg}$ and $\mathrm{Ca}$ for all the examined wheat types. In particular, the highest $\mathrm{K}$ average value was found for durum wheat $(4357.19 \pm 618.72 \mathrm{ppm})$, followed by wild wheat $(3864.32 \pm 561.39 \mathrm{ppm})$. On the other hand, the highest $\mathrm{Mg}$ content resulted for wild wheat, with a similar content for the two cultivation sites (1665.97 \pm 147.10 and $1651.89 \pm 203.23 \mathrm{ppm}$ for site A and B, respectively). Moreover, for durum wheat, a significantly lower value for $\mathrm{Mg}$ content was found in site B with respect to site A. Average Ca values were comparable in the two wheat types, with the highest content for durum wheat samples $(833.08 \pm 240.16 \mathrm{ppm})$ being significantly different from the durum wheat of site A $(731.11 \pm 295.70 \mathrm{ppm})$. It should be noted that for each type of tetraploid wheats, the average content of the macro-elements had the expected sequence $\mathrm{K}>\mathrm{Mg}>\mathrm{Ca}$ when considering both the harvesting sites [45]. Regarding micro-elements, in accordance with the literature data [27,37,45,46], higher levels of $\mathrm{Mn}, \mathrm{Fe}$ and $\mathrm{Zn}$ and lower $\mathrm{Cu}$ and $\mathrm{Cr}$, with $\mathrm{Ni}$ (Ni data not shown), in very low traces for all the samples were found in wild wheat. Interestingly, the highest $\mathrm{Mn}$ and Fe values were measured in wild wheat, followed by durum genotypes for both the harvesting sites. Generally higher values of Mn resulted in site A with respect to site B, while similar content of Fe was measured in the two sites. Very significant and site-dependent differences were found only for $\mathrm{Zn}$, with significantly higher levels for the three tetraploid subspecies in site B with respect to site A. Moreover, the highest Zn content was found in wild (32.86 $\pm 7.50 \mathrm{ppm})$, followed by durum (30.59 $\pm 3.69 \mathrm{ppm})$, all from site B. Finally, higher $\mathrm{Cd}$ and $\mathrm{Pb}$ levels were found in durum wheat genotypes, with the highest in samples of site $\mathrm{A}$ $(\mathrm{Cd}=0.10 \pm 0.04 \mathrm{ppm}, \mathrm{Pb}=0.09 \pm 0.04 \mathrm{ppm})$, followed by wild for both the two harvesting sites. 
Table 2. Average and standard deviation (SD) levels of macro-, micro- and toxic trace elements, calculated for the samples of three subspecies of tetraploid wheats (expressed as part per million, ppm) and for each site (A, Valenzano, Bari and B, Policoro, Matera). Tukey HSD test was applied for multiple comparisons of groups (wheat type). Letters $\left({ }^{a}, b\right)$ indicate significant differences for Tukey HSD test at least for $5 \%$ statistical probability ( ${ }^{a}$ significant difference between durum and wild in site A; $\mathrm{b}$ significant difference between durum and wild in site B). One-way ANOVA was applied to compare the means between the two cultivation sites (significant codes: ${ }^{* *} p$-value $<0.001$; $^{* *} p$-value $<0.01$; * $p$-value <0.05).

\begin{tabular}{|c|c|c|c|}
\hline Type of Wheat & & Durum & Wild \\
\hline \multicolumn{4}{|c|}{ Macroelements } \\
\hline \multirow[t]{2}{*}{$\mathrm{Ca}$} & A & $731.11 \pm 295.70 *$ & $728.73 \pm 181.26$ \\
\hline & B & $833.08 \pm 240.16^{*}$ & $836.73 \pm 232.90$ \\
\hline \multirow[t]{2}{*}{ K } & A & $3458.34 \pm 329.72 * * *$ & $3362.44 \pm 195.09 *$ \\
\hline & B & $4357.19 \pm 618.72 * * *, a$ & $3864.32 \pm 561.39 *, \mathrm{a}$ \\
\hline \multirow[t]{2}{*}{$\mathrm{Mg}$} & A & $1510.34 \pm 176.55^{* * *, \mathrm{a}}$ & $1665.97 \pm 147.10^{\mathrm{a}}$ \\
\hline & B & $1398.73 \pm 184.45^{* * *, b}$ & $1651.89 \pm 203.23^{b}$ \\
\hline \multicolumn{4}{|c|}{ Microelements } \\
\hline \multirow[t]{2}{*}{$\mathrm{Cr}$} & A & $0.05 \pm 0.06$ & $0.06 \pm 0.05$ \\
\hline & B & $0.03 \pm 0.02$ & $0.04 \pm 0.02$ \\
\hline \multirow[t]{2}{*}{$\mathrm{Cu}$} & A & $4.12 \pm 0.57^{* * *, \mathrm{a}}$ & $5.32 \pm 2.11^{\mathrm{a}}$ \\
\hline & B & $5.77 \pm 0.80^{* * *}$ & $5.29 \pm 0.63$ \\
\hline \multirow[t]{2}{*}{$\mathrm{Fe}$} & A & $33.31 \pm 6.87^{\mathrm{a}}$ & $38.51 \pm 3.77^{\mathrm{a}}$ \\
\hline & B & $31.96 \pm 12.75$ & $41.32 \pm 13.79$ \\
\hline \multirow[t]{2}{*}{ Mn } & A & $35.11 \pm 3.13^{* * *, \mathrm{a}}$ & $42.85 \pm 6.57^{* *, \mathrm{a}}$ \\
\hline & B & $26.93 \pm 3.89 * * *, \mathrm{~b}$ & $32.66 \pm 5.24 * *, b$ \\
\hline \multirow[t]{2}{*}{$\mathrm{Zn}$} & A & $14.03 \pm 1.75^{* * *, \mathrm{a}}$ & $16.35 \pm 2.34^{* * *, a}$ \\
\hline & B & $30.59 \pm 3.69 * * *, b$ & $32.86 \pm 7.50^{* * *, b}$ \\
\hline \multicolumn{4}{|c|}{ Toxic trace elements } \\
\hline \multirow[t]{2}{*}{$\mathrm{Cd}$} & A & $0.10 \pm 0.04^{* * *}$ & $0.08 \pm 0.03^{* * *}$ \\
\hline & B & $0.07 \pm 0.04^{* * *, \mathrm{a}}$ & $0.035 \pm 0.01^{* * *, \mathrm{a}}$ \\
\hline \multirow[t]{2}{*}{$\mathrm{Pb}$} & A & $0.09 \pm 0.04 * *$ & $0.08 \pm 0.03$ \\
\hline & B & $0.07 \pm 0.02 * *, \mathrm{~b}$ & $0.10 \pm 0.05^{b}$ \\
\hline
\end{tabular}

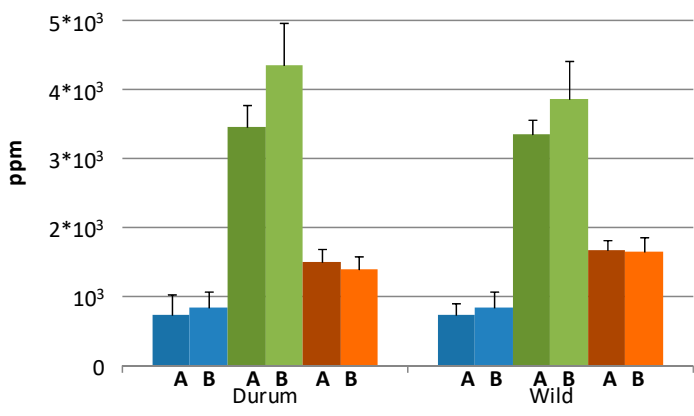

a)

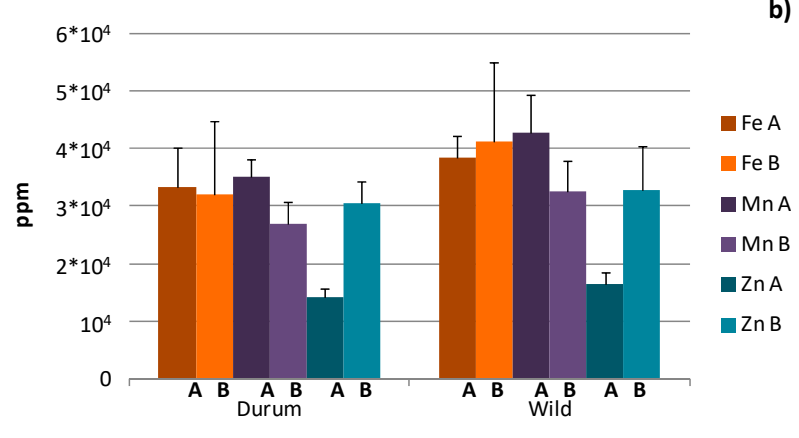

Figure 1. Average and standard deviation content of (a) macro- $(\mathrm{Ca}, \mathrm{K}, \mathrm{Mg})$ and (b) higher micro(Fe, $\mathrm{Zn}, \mathrm{Mn}$ ) elements, calculated for the samples of two types of wheat (expressed as part per million, ppm) and for each site (A, Valenzano, Bari and B, Policoro, Matera). 
A further level of investigation was performed by calculating the correlation matrix based on Pearson's coefficient for all the measured elements. An overview about the potential linear relationship between the metals (macronutrients, $\mathrm{Ca}, \mathrm{Mg}, \mathrm{K}$, micronutrients, $\mathrm{Zn}, \mathrm{Fe}, \mathrm{Cu}, \mathrm{Mn}$ and toxic trace elements, $\mathrm{Cd}, \mathrm{Pb}$ ) was obtained for each tetraploid genotype (durum and wild) and for each cultivation site, A and B (Tables 3-6). Although a simple correlation analysis, especially considering that a large data set should be carefully used for expressing nutrient relationships, we could find and will discuss a limited range of significant correlations that were obtained in this study. A high level of correlation was observed for durum wheat for both the two sites: in particular six couples of elements $(\mathrm{Cu} / \mathrm{Zn}, \mathrm{Mg} / \mathrm{Zn}$ with significance at $p<0.001$ and $\mathrm{Cu} / \mathrm{Mg}, \mathrm{Cu} / \mathrm{Mn}, \mathrm{Zn} / \mathrm{Mn}, \mathrm{Cr} / \mathrm{Fe}$ with significance at $p<0.01$ ) for site $\mathrm{A}$ and seven couples of elements $(\mathrm{K} / \mathrm{Cu}, \mathrm{K} / \mathrm{Mg}, \mathrm{K} / \mathrm{Mg}, \mathrm{Cu} / \mathrm{Mg}, \mathrm{Cu} / \mathrm{Mn}, \mathrm{Cr} / \mathrm{Fe}$ with significance at $p<0.001$ and $\mathrm{Ca} / \mathrm{Cd}$ with significance at $p<0.01$ ) for site $\mathrm{B}$ (Tables 3 and 5), while wild wheat showed a low number of correlations in both the two sites $(\mathrm{Cr} / \mathrm{Cu}, \mathrm{Fe} / \mathrm{Mn}$ with significance at $p<0.001$ and $\mathrm{Cr} / \mathrm{Fe}, \mathrm{Cr} / \mathrm{Mg}, \mathrm{Cd} / \mathrm{Mn}$ and $\mathrm{Ca} / \mathrm{Mg}$ with significance at $p<0.01$ for site $\mathrm{A} ; \mathrm{Cr} / \mathrm{Fe}$ with significance at $p<0.001$ and $\mathrm{Ca} / \mathrm{Cd}, \mathrm{K} / \mathrm{Zn}, \mathrm{K} / \mathrm{Cr}, \mathrm{K} / \mathrm{Fe}, \mathrm{Cr} / \mathrm{Fe}$ with significance at $p<0.01$ for site $\mathrm{B}$, Tables 4 and 6 ). It should also be noted that in some cases, more significant or positive correlation values for other elements (i.e., $\mathrm{Mn} / \mathrm{Mg}$ ) were expected, although comparable results to those that were obtained in this work were also reported in literature $[28,37,47,48]$.

Table 3. Pearson correlation matrix among all the variables of durum wheat genotypes grown in the A site (Valenzano, Bari). ${ }^{*},{ }^{* *},{ }^{* *}$ indicate significance at $p<0.05, p<0.01$ and $p<0.001$, respectively.

\begin{tabular}{cccccccccc}
\hline & $\mathbf{C a}$ & $\mathbf{K}$ & $\mathbf{C u}$ & $\mathbf{Z n}$ & $\mathbf{C r}$ & $\mathbf{F e}$ & $\mathbf{P b}$ & $\mathbf{C d}$ & $\mathbf{M g}$ \\
\hline $\mathbf{K}$ & 0.06 & & & & & & & & \\
$\mathbf{C u}$ & 0.03 & 0.23 & & & & & & & \\
$\mathbf{Z n}$ & -0.03 & 0.00 & $0.50^{* * *}$ & & & & & & \\
$\mathbf{C r}$ & 0.03 & 0.07 & $0.28^{*}$ & 0.09 & & & & & \\
$\mathbf{F e}$ & -0.05 & 0.08 & $0.28^{*}$ & 0.17 & $0.35^{* *}$ & & & & \\
$\mathbf{P b}$ & 0.11 & 0.05 & -0.01 & 0.10 & 0.18 & 0.08 & & & \\
$\mathbf{C d}$ & -0.20 & 0.21 & 0.09 & 0.17 & -0.08 & 0.22 & 0.03 & & \\
$\mathbf{M g}$ & 0.06 & $0.29^{*}$ & $0.39^{* *}$ & $0.45^{* * *}$ & $0.25^{*}$ & 0.22 & 0.13 & -0.02 & \\
$\mathbf{M n}$ & -0.04 & -0.17 & $0.36^{* *}$ & $0.36^{* *}$ & 0.20 & $0.27^{*}$ & 0.07 & $0.30^{*}$ & $0.29 *$ \\
\hline
\end{tabular}

Table 4. Pearson correlation matrix among all the variables of wild wheat genotypes grown in the A site (Valenzano, Bari). ${ }^{*}{ }^{* *},{ }^{* * *}$ indicate significance at $p<0.05, p<0.01$ and $p<0.001$, respectively.

\begin{tabular}{cccccccccc}
\hline & $\mathbf{C a}$ & $\mathbf{K}$ & $\mathbf{C u}$ & $\mathbf{Z n}$ & $\mathbf{C r}$ & $\mathbf{F e}$ & $\mathbf{P b}$ & $\mathbf{C d}$ & $\mathbf{M g}$ \\
\hline $\mathbf{K}$ & 0.14 & & & & & & & & \\
$\mathbf{C u}$ & -0.49 & -0.42 & & & & & & & \\
$\mathbf{Z n}$ & 0.46 & -0.16 & -0.41 & & & & & & \\
$\mathbf{C r}$ & -0.49 & -0.46 & $0.93^{* * *}$ & -0.20 & & & & & \\
$\mathbf{F e}$ & -0.08 & -0.41 & 0.61 & 0.19 & $0.80^{* *}$ & & & & \\
$\mathbf{P b}$ & 0.39 & -0.25 & -0.18 & 0.29 & 0.04 & 0.33 & & & \\
$\mathbf{C d}$ & 0.44 & -0.49 & 0.40 & 0.21 & 0.39 & 0.62 & 0.09 & & \\
$\mathbf{M g}$ & $0.66^{* *}$ & 0.34 & -0.45 & 0.10 & $-0.66^{* *}$ & -0.51 & -0.38 & 0.26 & \\
$\mathbf{M n}$ & 0.26 & -0.36 & 0.51 & 0.16 & 0.62 & $0.87^{* * *}$ & 0.33 & $0.80^{* *}$ & -0.18 \\
\hline
\end{tabular}

Table 5. Pearson correlation matrix among all the variables of durum wheat genotypes grown in the $\mathrm{B}$ site (Policoro, Matera). ${ }^{*}{ }^{* *},{ }^{* *}$ indicate significance at $p<0.05, p<0.01$ and $p<0.001$, respectively.

\begin{tabular}{cccccccccc}
\hline & $\mathbf{C a}$ & $\mathbf{K}$ & $\mathbf{C u}$ & $\mathbf{Z n}$ & $\mathbf{C r}$ & $\mathbf{F e}$ & $\mathbf{P b}$ & $\mathbf{C d}$ & $\mathbf{M g}$ \\
\hline $\mathbf{K}$ & 0.03 & & & & & & & & \\
$\mathbf{C u}$ & 0.03 & $0.55^{* * *}$ & & & & & & & \\
$\mathbf{Z n}$ & -0.01 & 0.72 & 0.60 & & & & & & \\
$\mathbf{C r}$ & -0.17 & -0.17 & $-0.27^{*}$ & -0.21 & & & & & \\
$\mathbf{F e}$ & -0.14 & 0.04 & -0.06 & -0.08 & $0.82^{* * *}$ & & & & \\
$\mathbf{P b}$ & 0.03 & -0.06 & -0.13 & 0.00 & 0.06 & -0.02 & & & \\
$\mathbf{C d}$ & $0.32^{* *}$ & $0.26^{*}$ & $0.29^{*}$ & $0.28^{*}$ & 0.00 & 0.05 & -0.10 & & \\
$\mathbf{M g}$ & 0.08 & $0.86^{* * *}$ & $0.46^{* * *}$ & 0.65 & -0.24 & -0.05 & -0.03 & $0.29^{*}$ & \\
$\mathbf{M n}$ & 0.12 & $0.46^{* * *}$ & $0.45^{* * *}$ & 0.54 & -0.20 & -0.05 & -0.17 & $0.21^{*}$ & $0.24^{*}$ \\
\hline
\end{tabular}


Table 6. Pearson correlation matrix among all the variables of wild wheat genotypes grown in the B site (Policoro, Matera). ${ }^{*}{ }^{* *},{ }^{* * *}$ indicate significance at $p<0.05, p<0.01$ and $p<0.001$, respectively.

\begin{tabular}{cccccccccc}
\hline & $\mathbf{C a}$ & $\mathbf{K}$ & $\mathbf{C u}$ & $\mathbf{Z n}$ & $\mathbf{C r}$ & $\mathbf{F e}$ & $\mathbf{P b}$ & $\mathbf{C d}$ & $\mathbf{M g}$ \\
\hline $\mathbf{K}$ & 0.48 & & & & & & & & \\
$\mathbf{C u}$ & 0.01 & 0.10 & & & & & & & \\
$\mathbf{Z n}$ & $0.62^{*}$ & $0.78^{* *}$ & 0.15 & & & & & & \\
$\mathbf{C r}$ & 0.09 & $0.73^{* *}$ & 0.49 & $0.67^{*}$ & & & & & \\
$\mathbf{F e}$ & 0.08 & $0.74^{* *}$ & $0.60^{*}$ & $0.65^{*}$ & $0.97^{* * *}$ & & & & \\
$\mathbf{P b}$ & -0.16 & -0.39 & 0.19 & -0.11 & -0.08 & -0.09 & & & \\
$\mathbf{C d}$ & $0.74^{* *}$ & 0.35 & 0.20 & 0.56 & 0.26 & 0.19 & -0.01 & & \\
$\mathbf{M g}$ & 0.20 & 0.44 & -0.08 & $0.70^{*}$ & 0.54 & 0.46 & 0.09 & 0.12 & \\
$\mathbf{M n}$ & 0.43 & 0.37 & 0.46 & 0.16 & 0.32 & 0.35 & -0.33 & 0.50 & -0.40 \\
\hline
\end{tabular}

Multivariate statistical analysis (PCA and OPLS-DA) was used to deeply investigate the variation in macronutrients $(\mathrm{Ca}, \mathrm{Mg}, \mathrm{K})$, micronutrients $(\mathrm{Zn}, \mathrm{Fe}, \mathrm{Cu}, \mathrm{Mn})$ and toxic trace elements $(\mathrm{Cd}, \mathrm{Pb})$ for the whole dataset of 25 wheat accessions and cultivars (three replicates for each cultivar studied) that is representative of durum and wild species in the two cultivation sites. The whole data were studied by OPLS-DA in order to evaluate the potential effect of the different pedoclimatic conditions on the wheat species (Figure 2). In particular, two OPLS-DA models were built using the same number of components (OPLS-DA model of site A: $1+2+0, R^{2} X=0.48, R^{2} Y=0.59$, $\mathrm{Q}^{2}=0.43, \mathrm{p}[$ CV-ANOVA $]=2.40612 \times 10^{-6}$; for OPLS-DA model of site $\mathrm{B}: 1+2+0, \mathrm{R}^{2} \mathrm{X}=0.56$, $\left.\mathrm{R}^{2} \mathrm{Y}=0.83, \mathrm{Q}^{2}=0.78, \mathrm{p}[\mathrm{CV}-\mathrm{ANOVA}]=2.10965 \times 10^{-19}\right)$. This approach showed that different pedoclimatic conditions characterize the two sites. Samples cultivated in site A (Valenzano, Bari) were homogeneously distributed in the space of the OPLS-DA graph, while those cultivated in site B (Policoro, Matera) appeared well differentiated in two groups (durum, wild).
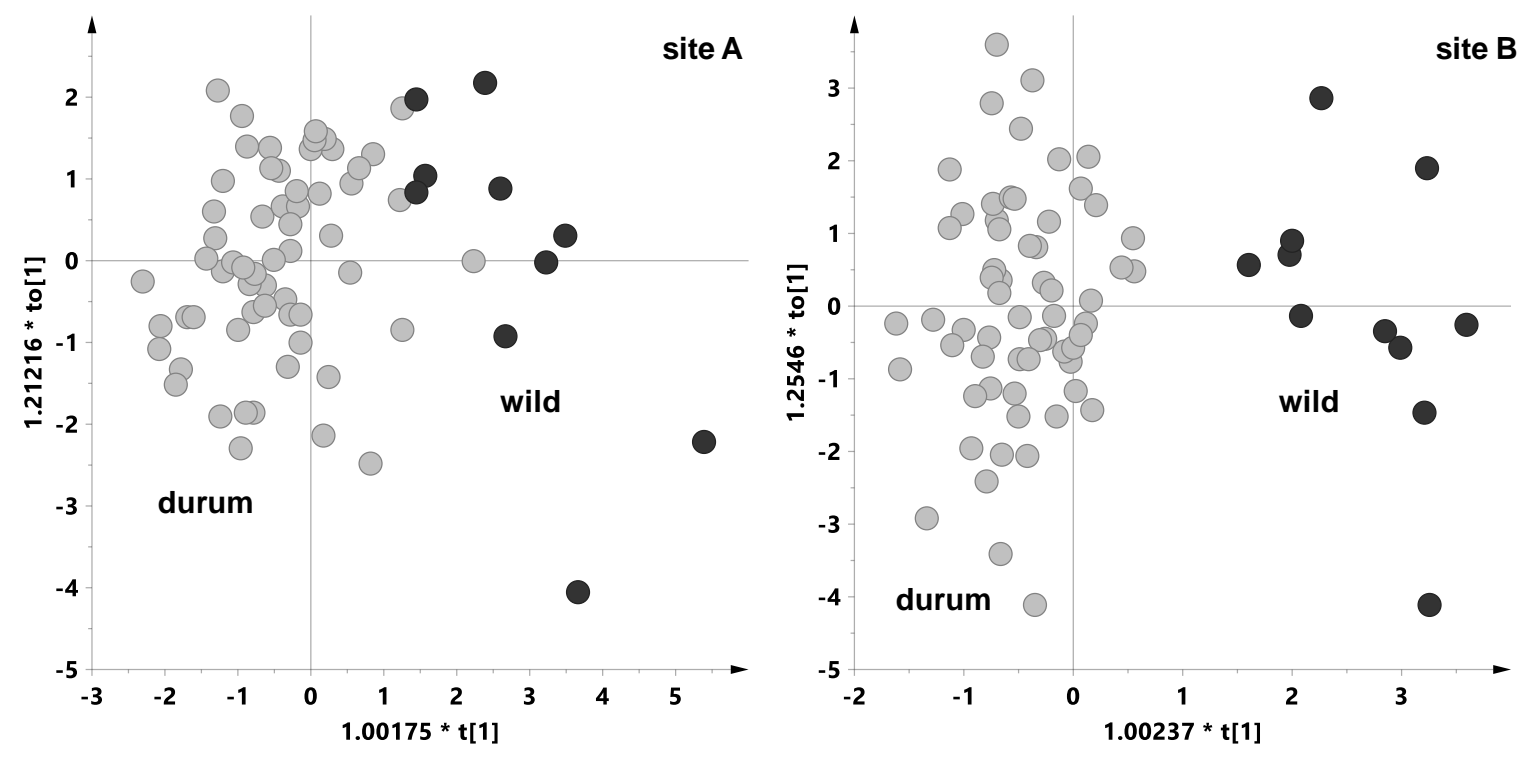

Figure 2. OPLS-DA scoreplots for each site (A, left, B, right). For OPLS-DA model of site A: $1+2+0$, $\mathrm{R}^{2} \mathrm{X}=0.48, \mathrm{R}^{2} \mathrm{Y}=0.59, \mathrm{Q}^{2}=0.43, \mathrm{p}[\mathrm{CV}-\mathrm{ANOVA}]=2.40612 \times 10^{-6}$; for OPLS-DA model of site B: $1+2+0, R^{2} X=0.56, R^{2} Y=0.83, Q^{2}=0.78, p[C V-A N O V A]=2.10965 \times 10^{-19}$.

With the aim to assess the different element uptake ability of the studied tetraploid wheat subspecies, an OPLS-DA analysis was performed for the whole data. In the first place, the dataset was analysed by differentiating in the model two different categories, the durum and the wild wheat types. The resulting OPLS-DA model, which was built with one predictive $(\mathrm{t}[1])$ and three orthogonal components $(1+3+0)$ beside the observed classification parameters for the two categories $\left(R^{2} X=0.58\right.$, $\mathrm{Q}^{2}=0.49$ ) gave an interesting hint for the sample distribution among the two sites (Figure 3). Indeed, 
this appears to be the natural discrimination $\left(R^{2} Y=0.53\right)$ observed in the first orthogonal component (to[1]). The colour encoded sample distribution among the two sites is clearly observed in Figure 3. The OPLS-DA scoreplot showed that durum wheat genotypes were mainly distributed at negative values of the predictive component $t[1]$, while the intra-class variation resulted in a large distribution of the data along the predictive component to[1] in a wide range of values (from -7 to 3 ). On the other hand, wild wheat accessions were clustered both at positive values of $t[1]$ and in a range of -2 and +2 of to[1].

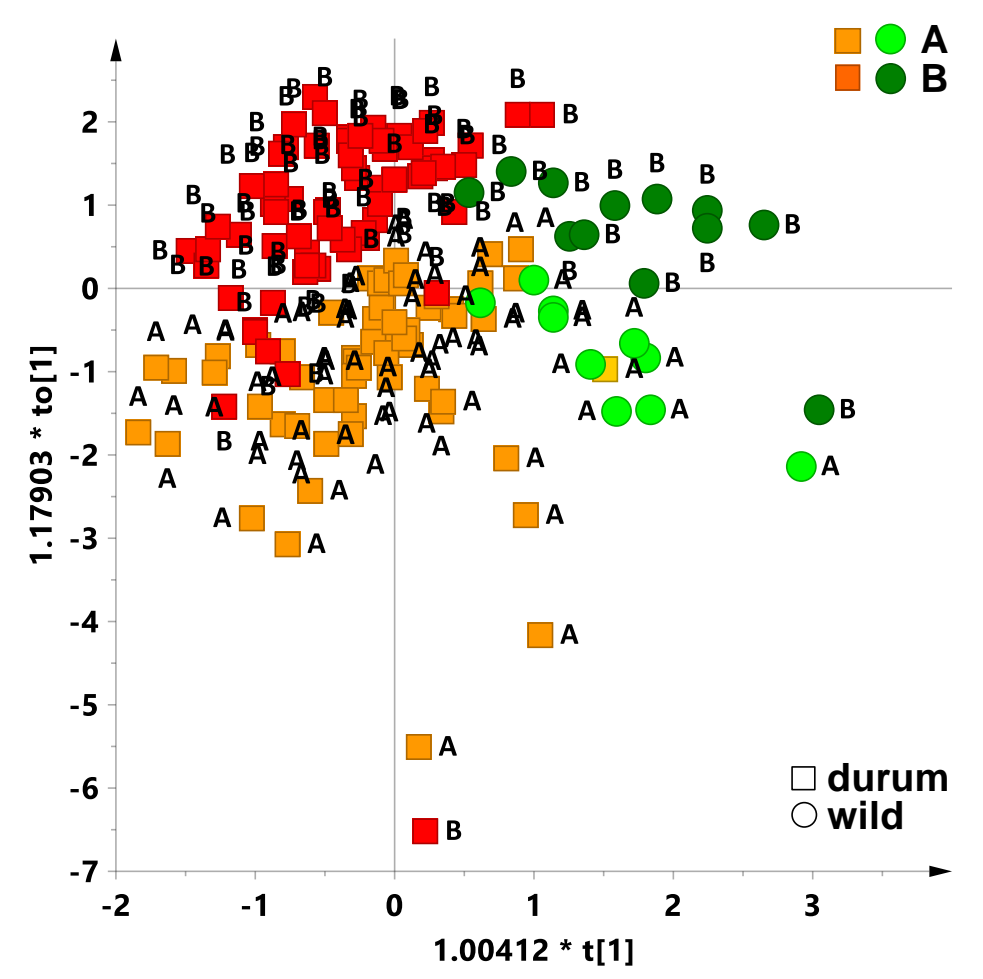

Figure 3. OPLS-DA scoreplot for the whole data considering the two sites (A and $\mathrm{B}$ ) as discriminating class $\left(1+3+0, R^{2} X=0.58, R^{2} Y=0.53, Q^{2}=0.49, p[C V-A N O V A]=3.9421 \times 10^{-17}\right)$.

A further MVA was then performed with the aim to differentiate, according to the cultivation site, durum and wild wheat types. For this purpose, two independent PCA and OPLS-DA models were built using the cultivation site as discrimination class. Both for the PCA (data not shown) and OPLS-DA (Figure 4) models, the two wheat groups resulted differently for the two cultivation sites. According to the OPLS-DA models that are depicted in Figure 4, and relative model parameters (in particular $\mathrm{Q}^{2}$ values), the more pronounced separation among the two cultivation sites was observed for durum $\left(Q^{2}=0.92\right)$ with respect to wild type $\left(Q^{2}=0.75\right)$ wheat. Moreover, due to a different sample size of durum (126 samples) in comparison with wild (22 samples) statistical models, a further cross check was applied to assess the soundness of the obtained parameters for the OPLS-DA models that are reported in Figure 4. By using the Weka open-source data mining software (v. 3.8.3, University of Waikato New Zealand) [49], a filter was applied to randomly remove a given percentage of samples from the durum sample set. For this purpose, $80 \%$ of durum samples were randomly excluded in order to obtain a comparable sample size for durum set (25) with respect to wild (22) samples. Subsequently, a Naïve Bayes classification was applied separately for both the durum and wild sets. The models' reliability (indicated with "Correctly Classified Instances" Tables S3 and S4), resulted with $87.5 \%$ and $71.4 \%$ for durum and wild samples, respectively, confirming our hypothesis that wild wheat is the less site sensitive species. This result suggested that a profitable search for the less site sensitive species had to be performed within the considered wild wheat cultivars. 

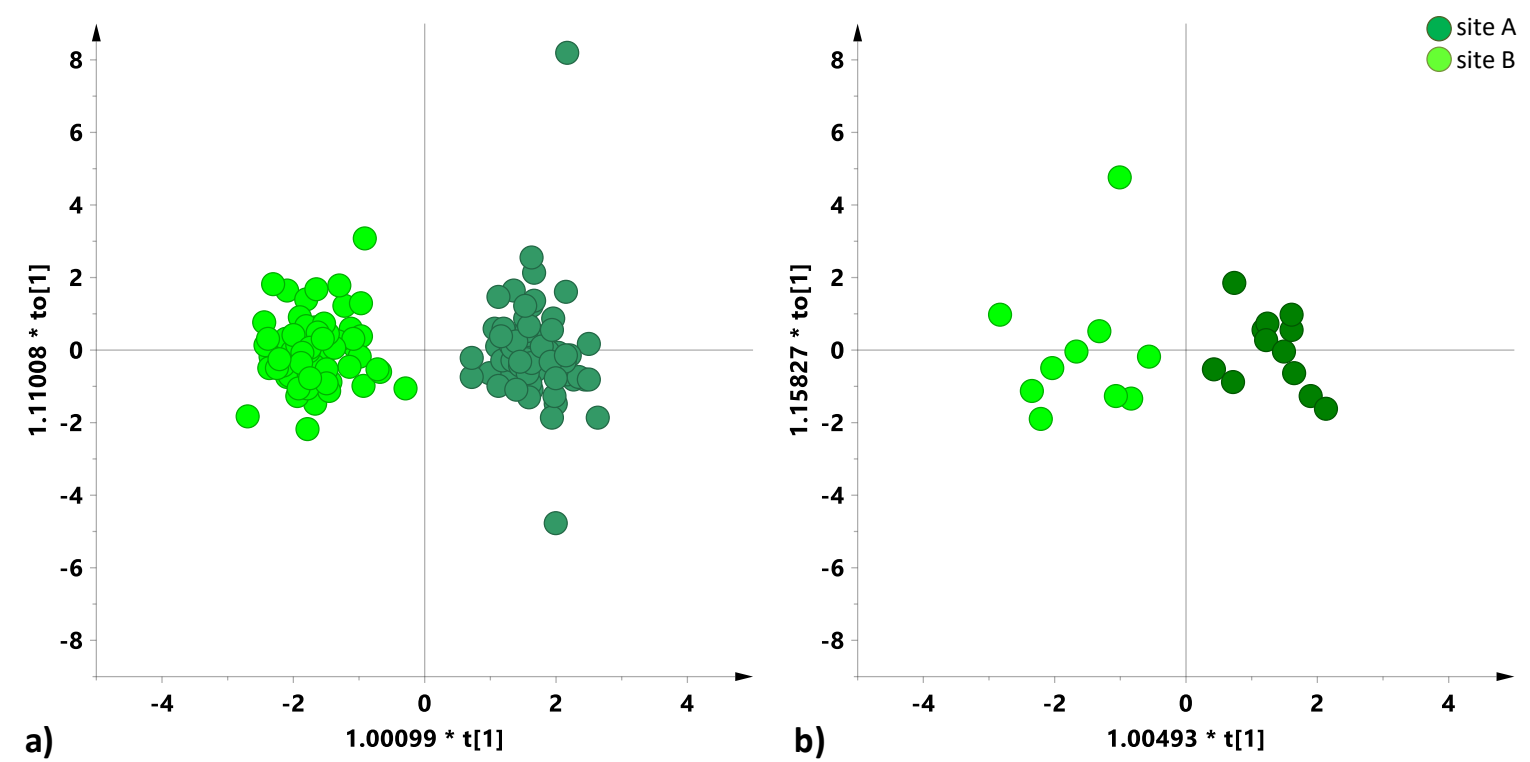

Figure 4. OPLS-DA scoreplots for each of the types of wheat (durum, wild) when they were considered separately in order to evaluate the effect of the site on the wheat species ((a). OPLS-DA model for durum wheat: $1+1+0, \mathrm{R}^{2} \mathrm{X}=0.453, \mathrm{R}^{2} \mathrm{Y}=0.933, \mathrm{Q}^{2}=0.921, \mathrm{p}[\mathrm{CV}-\mathrm{ANOVA}]=0 ;(\mathbf{b})$. OPLS-DA model for wild wheat: $1+1+0, R^{2} X=0.47, R^{2} Y=0.85, Q^{2}=0.75, p[C V-A N O V A]=6.05943 \times 10^{-5}$ ).

Finally, new OPLS-DA models were then calculated by using the four available data sets (three replicates for each of the two cultivation sites) for the four wild wheat accessions. The cultivation site was chosen as the discriminating class for each of the four OPLS-DA models. The obtained calculated quality model parameters are reported in Table 7, showing the lowest (MG29896) and highest (MG5323) cultivation site differentiation. Among the genotypes of wild wheat tetraploids, MG29896 resulted as the least affected from the cultivation site, having the lowest predictive ability, expressed as $Q^{2}$ value, followed by MG4330, MG5323.

Table 7. $R^{2} X, R^{2} Y$ and $Q^{2}$ parameters reported for every OPLS-DA model performed on the single wild tetraploid wheat genotypes (three replicates for each of the two cultivation sites).

\begin{tabular}{ccccc}
\hline Genotype & Model & $\mathbf{R}^{\mathbf{2}} \mathbf{X}$ & $\mathbf{R}^{\mathbf{2}} \mathbf{Y}$ & $\mathbf{Q}^{\mathbf{2}}$ \\
\hline MG5323 & $1+1+0$ & 0.66 & 0.99 & 0.94 \\
MG4343 & $1+1+0$ & 0.82 & 0.98 & 0.93 \\
MG4330 & $1+1+0$ & 0.81 & 0.95 & 0.85 \\
MG29896 & $1+1+0$ & 0.74 & 0.99 & 0.82 \\
\hline
\end{tabular}

\section{Discussion}

Variation in mineral micronutrient concentrations were found in the grains of wheat lines of diverse origin [50], and significant differences between wheat genotypes were found for grain Fe and Zn, however not Se concentration. Spelt, einkorn and emmer wheat appeared to contain higher Se concentration in their grains than bread and durum wheat. Other studies found that the genetic variability available in the modern wheat pool is moderate, and it would be necessary to use other wheat genetic resources in the breeding process [23]. In this respect, Cakmak et al. and Gomez-Becerra et al. $[19,22]$ have shown that the ssp. dicoccoides and ssp. dicoccum could be a good source of high micronutrients concentration [51]. Ficco et al. [52] estimated the magnitude of genotype $\times$ environment interaction effects in a collection of Italian durum wheat cultivars that were evaluated for the mineral elements concentration and suggested that the breeding activity for Fe and Zn would be difficult because $G \times E$ interaction is prevalent, though multi-location evaluation of germplasm collection might help to identify superior genotypes. 
Analysis of the contents of bioactive components in a wheat diversity panel grown in six diverse environments showed that the extent of variation due to variety and the environment differed significantly between components [53]. However, significant correlations were found between bioactive components and environmental factors, with even highly heritable components differing in amount between grain samples grown in different years on different sites [10]. Detailed analyses of bioactive components were carried out under the EU FP6 HEALTHGRAIN program on a wheat collection grown on a single site, and principal component analysis allowed us to classify the wheat genotypes on the basis of the bioactive components and to clearly separate wheat species (bread, durum, spelt, emmer and einkorn wheat) from related cereals (barley, rye and oats) [53]. It is also important to consider the evolutionary differences of wheat with different ploidy levels. Indeed, the comparison of photosynthesis and antioxidant defense systems in wheat with different ploidy levels showed significant differences in diploid, tetraploid and hexaploid wheats, suggesting an important regulatory role in photosystems and antioxidative systems of plants [16]. Several investigations have shown wide variation in phytochemical composition between genotypes, with important effects of environmental factors and genotypes $x$ environment interactions, and indicated that ancient wheats have health benefits compared with the current cultivated wheat. However, recent reviews on the health benefits of ancient and modern wheat have ascertained that most studies were not comparable in terms of genetic materials, growth conditions and processing, and reached the conclusion that further studies are required by different research groups and should consider a wider range of genotypes of ancient and modern wheat species grown together in the same field experiments [11,54].

In the present study, the data obtained by ICP-AES (macro-, micronutrients and toxic trace elements) were analyzed for different single wheat genotypes belonging to the three different T. turgidum wheat subspecies, under different pedoclimatic conditions (two sites, two growing seasons). The significantly higher content of $\mathrm{Mg}$ (among the macronutrients) and the highest levels of $\mathrm{Mn}, \mathrm{Fe}$ and $\mathrm{Zn}$ (among the micronutrients) were found for wild accessions with respect to durum wheat cultivars for both the two pedoclimatic conditions (two sites, two growing seasons). Moreover, wild types were also the wheat ones with the lowest level of accumulation of the trace toxic elements, in particular for $\mathrm{Cd}$ concentration. It should be noted that, in all the measured wheat samples, cadmium levels never exceeded the EU maximum allowed level of this contaminant in cereals and cereal products intended for human consumption (European Commission Regulation 2006) [55]. On the other hand, we found that among all the elements, the $\mathrm{Zn}$ levels that resulted were mainly affected by the cultivation site in all the measured wheat samples. This is mainly due to specific $\mathrm{Zn}$ bioaccumulation capacities of the soil [56] and, therefore, resulted in a very different uptake behaviour in the three wheat species, with the highest level in wild wheat species.

The above reported results, obtained by applying both correlation studies and multivariate analysis, also demonstrated that wild tetraploid wheats appeared the less affected from the pedoclimatic conditions which characterized the two cultivation sites (and their intrinsic mineral bioavailability).

Indeed, according to correlation studies, durum wheat appeared as the "most demanding" species (with respect to wild), showing a high number of correlations among elements for both the two cultivation sites. Therefore, for this intrinsic characteristic, durum wheat genotypes could be less prone to adaptation in different agricultural sites. The obtained results were also confirmed by the evidence that was also found by other authors [57-59], that both the concentrations of the analyzed elements and the relationships between them are species-specific. As reported in literature [55], antagonistic as well as synergistic interactions of elements are determined by the level of each nutrient, both in the soil and plant species, and sometimes even among cultivars of the same species, suggesting that some elements are translocated in plants in a similar way [37]. As a consequence, the hypothesis that the presence of a high level of correlations among elements (with consequent constraints in their uptake) could result in a wheat genotypes with a higher demanding character for simultaneous micro-nutrients availability could be reasonable. Finally, multivariate analysis (OPLS-DA) was also applied in order 
to establish the site dependence ranking among the considered durum and wild tetraploid wheats. For this reason, the statistic supervised model was built first using the durum and the wild wheat genotypes, and subsequently the cultivation site as the discriminating category. This approach allowed the focusing on the wild wheat species as the less site sensitive in the site dependence ranking. Despite the small sample size, multivariate analysis (OPLS-DA) was then applied in order to establish the existence of a ranking among all the studied wild cultivars. Consequently, OPLS-DA models using the two cultivation sites as a discriminating category were built for each of the wild wheat accessions and the obtained predictive ability (expressed by $Q^{2}$ values) that was evaluated. This operating system could be successfully used in order to reveal potential differences between the wild wheat genotypes with respect to their cultivation site-dependence [60]. Among the wild wheat types, the MG29896 accession was the least affected from the cultivation site, having the lowest $\mathrm{Q}^{2}$, followed by MG4330, MG4343, MG5323. The lowest predictability ( $\mathrm{Q}^{2}$ value) of the MG29896 OPLS-DA model corresponded to the lowest difference of samples, which were cultivated in two different pedoclimatic conditions (two sites, two growing seasons). Among the genotypes of the present study, wild appeared as the most remarkable for higher content of $\mathrm{Mg}$ (among the macronutrients), higher levels of $\mathrm{Mn}$, Fe and $\mathrm{Zn}$ (among the micronutrients) and lower level of $\mathrm{Cd}$ accumulation. According to correlation studies and MVA analyses, wild wheat also appeared the less demanding for simultaneous micro-nutrients availability and environmental conditions sensitivity. Therefore, the wild tetraploid wheats could be recommended for improvement and biofortification breeding programs in order to satisfy human nutrition requirements, as also reported by other authors [25-28,37,61]. Although both macro- and micro-nutrient concentration in wheat are very important for increasing the productivity and efficiency of a crop's yield, it is worth noting that micronutrient balance represents a very crucial point, since micronutrients deficiency in soil is a global phenomenon [62]. Therefore, bioavailability and their correlation should be considered [37]. In general, the present analysis of cultivar differences, and within wheat classes and subclasses, in different environmental conditions gave promising results. The differences are reflected in mineral concentration and absorption capability, and accumulation could also be useful in cross linkage studies. Nevertheless, further and more detailed studies are required, particularly on a wider range of genotypes of ancient and modern wheat species.

Supplementary Materials: The following are available online at http:/ /www.mdpi.com/2071-1050/11/3/736/s1.

Author Contributions: Formal analysis, L.D.C.; Investigation, B.L. and D.M.; Methodology, R.S. and F.P.F.; Resources, F.P.F.; Validation, D.M.; Visualization, L.D.C.; Writing-original draft, L.D.C., B.L. and G.M.; Writing-review \& editing, L.D.C. and F.P.F.

Funding: This research received no external funding.

Acknowledgments: This work was supported by PON (PONa3_00334) "Human and Environment Health Research 329 Center (2HE-Research Center). The authors gratefully acknowledge Prof. Antonio Blanco (Department of Soil, Plant \& Food Sciences, Genetics and Plant Breeding Section, University Aldo Moro, Bari, Italy) for critical reading of the manuscript.

Conflicts of Interest: The authors declare no conflict of interest.

\section{References}

1. Faostat, F. Statistical Databases; Food and Agriculture Organization of the United Nations: Rome, Italy, 2018.

2. Shewry, P.R.; Hey, S.J. The contribution of wheat to human diet and health. Food Energy Secur. 2015, 4, 178-202. [PubMed]

3. Shewry, P.R.; Hey, S. Do "ancient" wheat species differ from modern bread wheat in their contents of bioactive components? J. Cereal Sci. 2015, 65, 236-243. [CrossRef]

4. Uauy, C.; Distelfeld, A.; Fahima, T.; Blechl, A.; Dubcovsky, J. A NAC gene regulating senescence improves grain protein, zinc, and iron content in wheat. Science 2006, 314, 1298-1301. [CrossRef] [PubMed]

5. Faris, J.D. Wheat domestication: Key to agricultural revolutions past and future. In Genomics of Plant Genetic Resources; Springer: Berlin, Germany, 2014; pp. 439-464. 
6. Filipčev, B.; Kojić, J.; Krulj, J.; Bodroža-Solarov, M.; Ilić, N. Betaine in cereal grains and grain-based products. Foods 2018, 7, 49. [CrossRef]

7. Merah, O.; Deleens, E.; Nachit, M.; Monneveux, P. Carbon isotope discrimination, leaf characteristics and grain yield of interspecific wheat lines and their durum parents under Mediterranean conditions. Cereal Res. Commun. 2001, 29, 143-149.

8. Merah, O.; Deleens, E.; Al Hakimi, A.; Monneveux, P. Carbon isotope discrimination and grain yield variations among tetraploid wheat species cultivated under contrasting precipitation regimes. J. Agron. Crop Sci. 2001, 186, 129-134. [CrossRef]

9. Merah, O. Carbon isotope discrimination and mineral composition of three organs in durum wheat genotypes grown under Mediterranean conditions. Comptes Rendus De L'académie Des Sci. 2001, 324, 355-363. [CrossRef]

10. Shewry, P.R.; Hawkesford, M.J.; Piironen, V.; Lampi, A.-M.; Gebruers, K.; Boros, D.; Andersson, A.A.; Åman, P.; Rakszegi, M.; Bedo, Z. Natural variation in grain composition of wheat and related cereals. J. Agric. Food Chem. 2013, 61, 8295-8303. [CrossRef] [PubMed]

11. Shewry, P.R. Do ancient types of wheat have health benefits compared with modern bread wheat? J. Cereal Sci. 2017, 79, 469-476. [CrossRef]

12. Kärkkäinen, O.; Lankinen, M.A.; Vitale, M.; Jokkala, J.; Leppänen, J.; Koistinen, V.; Lehtonen, M.; Giacco, R.; Rosa-Sibakov, N.; Micard, V.; et al. Diets rich in whole grains increase betainized compounds associated with glucose metabolism. Am. J. Clin. Nutr. 2018, 108, 971-979. [CrossRef]

13. Godfrey, D.; Hawkesford, M.J.; Powers, S.J.; Millar, S.; Shewry, P.R. Effects of crop nutrition on wheat grain composition and end use quality. J. Agric. Food Chem. 2010, 58, 3012-3021. [CrossRef] [PubMed]

14. Laddomada, B.; Caretto, S.; Mita, G. Wheat bran phenolic acids: Bioavailability and stability in whole wheat-based foods. Molecules 2015, 20, 15666-15685. [CrossRef] [PubMed]

15. Laddomada, B.; Durante, M.; Minervini, F.; Garbetta, A.; Cardinali, A.; D’Antuono, I.; Caretto, S.; Blanco, A.; Mita, G. Phytochemical composition and anti-inflammatory activity of extracts from the whole-meal flour of Italian durum wheat cultivars. Int. J. Mol. Sci. 2015, 16, 3512-3527. [CrossRef] [PubMed]

16. Brestic, M.; Zivcak, M.; Hauptvogel, P.; Misheva, S.; Kocheva, K.; Yang, X.; Li, X.; Allakhverdiev, S.I. Wheat plant selection for high yields entailed improvement of leaf anatomical and biochemical traits including tolerance to non-optimal temperature conditions. Photosynth. Res. 2018, 136, 245-255. [CrossRef] [PubMed]

17. Mao, H.; Chen, M.; Su, Y.; Wu, N.; Yuan, M.; Yuan, S.; Brestic, M.; Zivcak, M.; Zhang, H.; Chen, Y. Comparison on Photosynthesis and Antioxidant Defense Systems in Wheat with Different Ploidy Levels and Octoploid Triticale. Int. J. Mol. Sci. 2018, 19, 3006. [CrossRef] [PubMed]

18. Laddomada, B.; Durante, M.; Mangini, G.; D’Amico, L.; Lenucci, M.S.; Simeone, R.; Piarulli, L.; Mita, G.; Blanco, A. Genetic variation for phenolic acids concentration and composition in a tetraploid wheat (Triticum turgidum L.) collection. Genet. Resour. Crop Evol. 2017, 64, 587-597. [CrossRef]

19. Gomez-Becerra, H.F.; Yazici, A.; Ozturk, L.; Budak, H.; Peleg, Z.; Morgounov, A.; Fahima, T.; Saranga, Y.; Cakmak, I. Genetic variation and environmental stability of grain mineral nutrient concentrations in Triticum dicoccoides under five environments. Euphytica 2010, 171, 39-52. [CrossRef]

20. Velu, G.; Singh, R.; Arun, B.; Mishra, V.; Tiwari, C.; Joshi, A.; Virk, P.; Cherian, B.; Pfeiffer, W. Reaching out to farmers with high Zinc wheat varieties through public-private partnerships-An Experience from Eastern-Gangetic Plains of India. Adv. Food Technol. Nutr. Sci 2015, 1, 73-75. [CrossRef]

21. Guzmán, C.; Medina-Larqué, A.S.; Velu, G.; González-Santoyo, H.; Singh, R.P.; Huerta-Espino, J.; Ortiz-Monasterio, I.; Peña, R.J. Use of wheat genetic resources to develop biofortified wheat with enhanced grain zinc and iron concentrations and desirable processing quality. J. Cereal Sci. 2014, 60, 617-622. [CrossRef]

22. Cakmak, I.; Pfeiffer, W.H.; McClafferty, B. Biofortification of durum wheat with zinc and iron. Cereal Chem. 2010, 87, 10-20. [CrossRef]

23. Magallanes-López, A.M.; Hernandez-Espinosa, N.; Velu, G.; Posadas-Romano, G.; Ordoñez-Villegas, V.M.G.; Crossa, J.; Ammar, K.; Guzmán, C. Variability in iron, zinc and phytic acid content in a worldwide collection of commercial durum wheat cultivars and the effect of reduced irrigation on these traits. Food Chem. 2017, 237, 499-505. [CrossRef] [PubMed]

24. Yan, J.; Xue, W.-T.; Yang, R.-Z.; Qin, H.-B.; Zhao, G.; Tzion, F.; Cheng, J.-P. Quantitative Trait Loci Conferring Grain Selenium Nutrient in Durum Wheat $\times$ Wild Emmer Wheat RIL Population. Czech J. Genet. Plant Breed. 2018, 54, 52-58. [CrossRef] 
25. Awan, S.; Ahmad, S.; Ali, M.; Ahmed, M.; Rao, A. Use of multivariate analysis in determining characteristics for grain yield selection in wheat. Sarhad J. Agric. 2015, 31, 139-150. [CrossRef]

26. Shewry, P.R.; Pellny, T.K.; Lovegrove, A. Is modern wheat bad for health. Nat. Plants 2016, 2, 16097. [CrossRef] [PubMed]

27. Arzani, A.; Ashraf, M. Cultivated Ancient Wheats (Triticum spp.): A Potential Source of Health-Beneficial Food Products. Compr. Rev. Food Sci. Food Saf. 2017, 16, 477-488. [CrossRef]

28. Murphy, K.M.; Reeves, P.G.; Jones, S.S. Relationship between yield and mineral nutrient concentrations in historical and modern spring wheat cultivars. Euphytica 2008, 163, 381-390. [CrossRef]

29. Kaur, K.D.; Jha, A.; Sabikhi, L.; Singh, A. Significance of coarse cereals in health and nutrition: A review. J. Food Sci. Technol. 2014, 51, 1429-1441. [CrossRef]

30. Srinivasa, J.; Arun, B.; Mishra, V.K.; Singh, G.P.; Velu, G.; Babu, R.; Vasistha, N.K.; Joshi, A.K. Zinc and iron concentration QTL mapped in a Triticum spelta $\times$ T. aestivum cross. Theor. Appl. Genet. 2014, 127, 1643-1651. [CrossRef]

31. Pasqualone, A.; Piarulli, L.; Mangini, G.; Gadaleta, A.; Blanco, A.; Simeone, R. Quality characteristics of parental lines of wheat mapping populations. Agric. Food Sci. 2015, 24, 118-127. [CrossRef]

32. Mzid, N.; Todorovic, M.; Albrizio, R.; Cantore, V. Remote Sensing Based Monitoring of Durum Wheat under Water Stress Treatments; Spatial Analysis and GEOmatics: Rouen, France, 2017.

33. Scortichini, M.; Jianchi, C.; De Caroli, M.; Dalessandro, G.; Pucci, N.; Modesti, V.; L'Aurora, A.; Petriccione, M.; Zampella, L.; Mastrobuoni, F.; et al. A zinc, copper and citric acid biocomplex shows promise for control of Xylella fastidiosa subsp. pauca in olive trees in Apulia region (southern Italy). Phytopathol. Mediterr. 2018, 57, $48-72$.

34. R Development Core Team. R: A Language and Environment for Statistical Computing; R Foundation for Statistical Computing: Vienna, Austria, 2013.

35. Xia, J.; Psychogios, N.; Young, N.; Wishart, D.S. MetaboAnalyst: A web server for metabolomic data analysis and interpretation. Nucleic Acids Res. 2009, 37, W652-W660. [CrossRef]

36. Xia, J.; Wishart, D.S. Using MetaboAnalyst 3.0 for comprehensive metabolomics data analysis. Curr. Protoc. Bioinform. 2016, 55. [CrossRef] [PubMed]

37. Pandey, A.; Khan, M.K.; Hakki, E.E.; Thomas, G.; Hamurcu, M.; Gezgin, S.; Gizlenci, O.; Akkaya, M.S. Assessment of genetic variability for grain nutrients from diverse regions: Potential for wheat improvement. SpringerPlus 2016, 5, 1912. [CrossRef] [PubMed]

38. Hauke, J.; Kossowski, T. Comparison of values of Pearson's and Spearman's correlation coefficients on the same sets of data. Quaest. Geogr. 2011, 30, 87-93. [CrossRef]

39. Bro, R.; Smilde, A.K. Principal component analysis. Anal. Methods 2014, 6, 2812-2831. [CrossRef]

40. Trygg, J.; Wold, S. Orthogonal projections to latent structures (O-PLS). J. Chemom. 2002, 16, 119-128. [CrossRef]

41. Triba, M.N.; Le Moyec, L.; Amathieu, R.; Goossens, C.; Bouchemal, N.; Nahon, P.; Rutledge, D.N.; Savarin, P. PLS/OPLS models in metabolomics: The impact of permutation of dataset rows on the K-fold cross-validation quality parameters. Mol. Biosyst. 2015, 11, 13-19. [CrossRef] [PubMed]

42. Aru, V.; Pisano, M.B.; Savorani, F.; Engelsen, S.B.; Cosentino, S.; Marincola, F.C. Data on the changes of the mussels' metabolic profile under different cold storage conditions. Data Brief 2016, 7, 951-957. [CrossRef] [PubMed]

43. Wheelock, Å.M.; Wheelock, C.E. Trials and tribulations of 'omics data analysis: Assessing quality of SIMCA-based multivariate models using examples from pulmonary medicine. Mol. Biosyst. 2013, 9, 2589-2596. [CrossRef] [PubMed]

44. Pettigrew, W.T. Potassium influences on yield and quality production for maize, wheat, soybean and cotton. Physiol. Plant. 2008, 133, 670-681. [CrossRef]

45. Tejera, R.L.; Luis, G.; González-Weller, D.; Caballero, J.M.; Gutiérrez, Á.J.; Rubio, C.; Hardisson, A. Metals in wheat flour; comparative study and safety control. Nutr. Hosp. 2013, 28, 506-513. [PubMed]

46. Garnett, T.P.; Graham, R.D. Distribution and remobilization of iron and copper in wheat. Ann. Bot. 2005, 95, 817-826. [CrossRef] [PubMed]

47. Peleg, Z.; Cakmak, I.; Ozturk, L.; Yazici, A.; Jun, Y.; Budak, H.; Korol, A.B.; Fahima, T.; Saranga, Y. Quantitative trait loci conferring grain mineral nutrient concentrations in durum wheat $\times$ wild emmer wheat RIL population. Theor. Appl. Genet. 2009, 119, 353-369. [CrossRef] [PubMed] 
48. Hakki, E.E.; Dograr, N.; Pandey, A.; Khan, M.K.; Hamurcu, M.; Kayis, S.A.; Gezgin, S.; ÖLMEZ, F.; Akkaya, M.S. Molecular and elemental characterization of selected Turkish durum wheat varieties. Not. Bot. Horti Agrobot. Cluj-Napoca 2014, 42, 431-439. [CrossRef]

49. Witten, I.H.; Frank, E.; Hall, M.A.; Pal, C.J. Data Mining: Practical Machine Learning Tools and Techniques; Morgan Kaufmann: San Francisco, CA, USA, 2016.

50. Zhao, F.; Su, Y.; Dunham, S.; Rakszegi, M.; Bedo, Z.; McGrath, S.; Shewry, P. Variation in mineral micronutrient concentrations in grain of wheat lines of diverse origin. J. Cereal Sci. 2009, 49, 290-295. [CrossRef]

51. Monasterio, I.; Graham, R.D. Breeding for trace minerals in wheat. Food Nutr. Bull. 2000, 21, 392-396. [CrossRef]

52. Ficco, D.; Riefolo, C.; Nicastro, G.; De Simone, V.; Di Gesu, A.; Beleggia, R.; Platani, C.; Cattivelli, L.; De Vita, P. Phytate and mineral elements concentration in a collection of Italian durum wheat cultivars. Field Crop. Res. 2009, 111, 235-242. [CrossRef]

53. Shewry, P.R.; Piironen, V.; Lampi, A.-M.; Edelmann, M.; Kariluoto, S.; Nurmi, T.; Fernandez-Orozco, R.; Andersson, A.A.; Åman, P.; Fras, A. Effects of genotype and environment on the content and composition of phytochemicals and dietary fiber components in rye in the HEALTHGRAIN diversity screen. J. Agric. Food Chem. 2010, 58, 9372-9383. [CrossRef]

54. Dinu, M.; Whittaker, A.; Pagliai, G.; Benedettelli, S.; Sofi, F. Ancient wheat species and human health: Biochemical and clinical implications. J. Nutr. Biochem. 2018, 52, 1-9. [CrossRef]

55. Fageria, V. Nutrient interactions in crop plants. J. Plant Nutr. 2001, 24, 1269-1290. [CrossRef]

56. He, Z.L.; Yang, X.E.; Stoffella, P.J. Trace elements in agroecosystems and impacts on the environment. J. Trace Elem. Med. Biol. 2005, 19, 125-140. [CrossRef] [PubMed]

57. Suchowilska, E.; Wiwart, M.; Kandler, W.; Krska, R. A comparison of macro-and microelement concentrations in the whole grain of four Triticum species. Plant Soil Environ. 2012, 58, 141-147. [CrossRef]

58. Moreira-Ascarrunz, S.D.; Larsson, H.; Prieto-Linde, M.L.; Johansson, E. Mineral nutritional yield and nutrient density of locally adapted wheat genotypes under organic production. Foods 2016, 5, 89. [CrossRef] [PubMed]

59. Matthews, S.B.; Santra, M.; Mensack, M.M.; Wolfe, P.; Byrne, P.F.; Thompson, H.J. Metabolite profiling of a diverse collection of wheat lines using ultraperformance liquid chromatography coupled with time-of-flight mass spectrometry. PLoS ONE 2012, 7, e44179. [CrossRef] [PubMed]

60. Righetti, L.; Rubert, J.; Galaverna, G.; Folloni, S.; Ranieri, R.; Stranska-Zachariasova, M.; Hajslova, J.; Dall'Asta, C. Characterization and discrimination of ancient grains: A metabolomics approach. Int. J. Mol. Sci. 2016, 17, 1217. [CrossRef] [PubMed]

61. Garcia-Oliveira, A.L.; Chander, S.; Ortiz, R.; Menkir, A.; Gedil, M. Genetic basis and breeding perspectives of grain iron and zinc enrichment in cereals. Front. Plant Sci. 2018, 9, 937. [CrossRef] [PubMed]

62. Dimkpa, C.O.; Bindraban, P.S. Fortification of micronutrients for efficient agronomic production: A review. Agron. Sustain. Dev. 2016, 36, 7. [CrossRef]

(C) 2019 by the authors. Licensee MDPI, Basel, Switzerland. This article is an open access article distributed under the terms and conditions of the Creative Commons Attribution (CC BY) license (http:/ / creativecommons.org/licenses/by/4.0/). 